\title{
Use it or lose it: measuring trends in wild species subject to substantial use
}

\author{
Megan Tierney, Rosamunde Almond, Damon Staniell-Smith, Louise McRae \\ Christoph Zöckler, Ben Collen, Matt Walpole, Jon Hutton and Stevende Bie
}

\begin{abstract}
The unsustainable use of wild animals and plants is thought to be a significant driver of biodiversity loss in many regions of the world. The international community has therefore called for action to ensure the sustainable use of living resources and safeguard them for future generations. Indicators that can track changes in populations of species used by humans are essential tools for measuring progress towards these ideals and informing management decisions. Here we present two indicators that could be used to track changes in populations of utilized vertebrate species and levels of harvest sustainability. Preliminary results based on sample data both at the global level and for the Arctic show that utilized species are faring better than other species overall. This could be a consequence of better management of these populations, as indicated by more sustainable harvest levels in recent decades. Limitations of the indicators are still apparent; in particular, there is a lack of data on harvested populations of some vertebrate classes and from certain regions. Focusing monitoring efforts on broadening the scope of data collected and identifying interactions with other potential drivers of decline will strengthen these indicators as policy tools and improve their potential to be incorporated into future sets of indicators to track progress towards global biodiversity targets.
\end{abstract}

Keywords Aichi Targets, Arctic, biodiversity indicators, Convention on Biological Diversity, population trends, sustainable use

This paper contains supplementary material that can be found online at http://journals.cambridge.org

\footnotetext{
Megan Tierney (Corresponding author), Rosamunde Almond*, Damon Stanwell-Smith, Christoph Zöckler, Matt Walpole and Jon Hutton United Nations Environment Programme World Conservation Monitoring Centre, 219 Huntingdon Road, Cambridge, CB3 0DL, UK. E-mail Megan. Tierney@unep-wcmc.org

LouISE MCRAE and BEN Collen ${ }^{\dagger}$ Institute of Zoology, Zoological Society of London, London, UK

STEVEN DE BIE Resource Ecology Group, Wageningen University, Wageningen, The Netherlands

${ }^{*}$ Current address: Cambridge Forum for Sustainability and the Environment, Department of Applied Mathematics and Theoretical Physics (DAMTP), Centre for Mathematical Sciences, University of Cambridge, UK

${ }^{\dagger}$ Current address: Centre for Biodiversity \& Environment Research, University College London, UK

Received 30 July 2012. Revision requested 22 November 2012.

Accepted 5 April 2013. First published online 13 March 2014.
}

\section{Introduction}

The use of wild animals and plants is often essential 1 for human livelihoods and well-being, while in some situations it is considered an active choice (Hutton \& Leader-Williams, 2003). In many regions the use of wild resources is thought to be unsustainable and a major driver of biodiversity loss (Butchart, 2008; Baillie et al., 2010). As the world's human population increases and demand for biological resources grows, the pressure that humans exert on exploited species and their ecosystems will become greater. For wild species to meet our needs now and in the future it is vital that they are used in a biologically sustainable way.

Sustainable use is defined by the Convention on Biological Diversity (CBD) as the 'use of components of biological diversity in a way and at a rate that does not lead to the long-term decline of biodiversity, thereby maintaining its potential to meet the needs and aspirations of present and future generations' (CBD, 1992). Sustainable use was a focal area for the CBD target of significantly reducing biodiversity loss by 2010 (Decision VII/30). Having failed to meet this target the Parties to the CBD adopted a revised Strategic Plan for addressing biodiversity loss (CBD, 2010a). It includes 20 measurable targets (the Aichi Targets) and maintains the goal of sustainable use.

Building on the existing CBD indicator framework, the CBD has called for the development of a new suite of indicators that can be used to track progress towards targets set in the Strategic Plan (CBD, 2010b). In conjunction with a new suite of indicators, it has been recommended that consideration be given to how indicators can be linked or presented as integrated sets (Walpole et al., 2009; Butchart et al., 2010; Sparks et al., 2011). Sparks et al. (2011) showed that linking indicators can create a more comprehensive understanding of trends and patterns and aid in communicating complex messages, and that linked indicator sets can provide decision-makers with a tool for effectively addressing biodiversity loss.

To determine whether the use of wild species is biologically sustainable, any indicator or set of indicators must reflect the status and trends of species in the wild, as well as the effect of harvesting on the species. Despite the known importance of wild species to economies and livelihoods, relatively few indicators have been developed specifically to monitor the species that people use and there 
have been few attempts to examine how indicators of species use and harvest sustainability could be linked to provide a broader picture of what, where and how people are using wild species.

Here we develop an indicator that can track change in populations of species that are utilized by humans (Utilized Species Index) and an indicator that tracks sustainability of the harvest of a selection of utilized species (Harvest Index) and examine their feasibility as effective and robust indicators of the sustainable use of biodiversity. Firstly we present trends in the Utilized Species Index at a global scale. We then use a case study to critically examine how the Harvest Index and the Utilized Species Index can be used together to provide a more thorough understanding of the state of utilized species in the Arctic, which is rich in biodiversity but where species are subject to high levels of exploitation.

Arctic biodiversity is particularly vulnerable to the pressures of commercial, subsistence and traditional harvesting and trade of wild species because many are concentrated in limited areas of biological productivity, such as polynias and coastal plains. This adds to the existing pressure from rapid environmental change, such as that of sea-ice extent (Gleason \& Rode, 2009; CAFF, 2010; HeideJørgensen et al., 2010; Kovacs et al., 2010). Hence there is growing concern that because of the limited functional redundancy in Arctic ecosystems the loss of a single species could have cascading effects on the state and function of the entire system (Post et al., 2009).

The Conservation of Arctic Flora and Fauna working group, through the Circumpolar Biodiversity Monitoring Programme, is coordinating a number of programmes and projects to assess biodiversity status and trends and improve understanding of the drivers of change, and of management options (Gill et al., 2008). One important contribution to this, and to tracking the response of Arctic wildlife to growing pressures, has been the development of the Arctic Species Trend Index (McRae et al., 2010). This is the disaggregation of the Living Planet Index for the Arctic (Loh et al., 2005; Collen et al., 2009), which tracks trends in vertebrate populations. In the case study we examine whether the indicators we have developed can be applied to track changes in Arctic species that are utilized by people and whether the indicators can complement the Arctic Species Trend Index, providing further information for managing species populations.

\section{Methods}

We developed two indicators for wild commodities: the Utilized Species Index and the Harvest Index. The first is based on the Living Planet Index (Loh et al., 2005; Collen et al., 2009) and tracks changes that have occurred since
1970 in populations of vertebrate species utilized by humans. The second combines population and harvest data to track the sustainability of the harvest of a selection of utilized vertebrate species.

\section{Utilized Species Index}

Selection of species We sourced vertebrate population data from the Living Planet Index and Arctic Species Trend Index databases, as compiled in October 2010, and coded general information on each population, including vertebrate class, system (freshwater, marine, terrestrial) and the zone (Living Planet Index: temperate, tropical; Arctic Species Trend Index: polar) on which it is most dependent for survival and reproduction (Loh et al., 2005; Collen et al., 2009).

A decision tree (Supplementary Material 1) was used to further code species within the Living Planet Index database as utilized by humans, based on cross-referencing information on the use of each species from a variety of publicly available sources, including the IUCN Red List (IUCN, 2009), the World Bird Database (Avibase, 2009), the CITES trade database (CITES, 2009), forestry country profiles from the Food and Agriculture Organization of the United Nations (FAO, 2009a), the International Tropical Timber Organization (ITTO, 2009), the Center for International Forestry Research (CIFOR, 2009), the University of British Columbia Sea Around Us Project (UBC, 2009), and the FishBase database (Froese \& Pauly, 2009). The coding generated a database of utilized species.

The type of use of each species was categorized, where possible, according to the IUCN utilization classification scheme (IUCN, 2009) as food (for humans or animals), medicine, poison, manufacturing chemicals, other chemicals, fuels, fibre, construction/structural materials, wearing apparel, household goods, handicrafts, pets, research, sport hunting, other and unknown. These categories are not mutually exclusive. As sample sizes were small in some categories, we restricted our analysis to the use of species as food for humans, for sport hunting, or as pets.

Species that are widely used and are particularly important to people were also categorized as substantially used. Information on the scale of trade or volume of harvest at local, national, regional and international levels was obtained from the aforementioned sources as well as the global Forestry Resources Assessments (FAO, 2009b), regional reports and expert knowledge (IUCN Sustainable Use Steering Group, pers. comm.). Evidence for each species was ranked subjectively from 1 to 5 , where 1 equated to a low amount of evidence for substantial use and 5 equated to a high amount of evidence for substantial use. This process generated a list of substantially used species. Trend analyses were only conducted on species with evidence scores $\geqslant 3$. 
TABlE 1 Descriptions of each index generated, with species and population numbers. A breakdown of the number of species and populations in each index by system (freshwater, marine, terrestrial), zone (temperate, tropical) and vertebrate class (amphibian, bird, fish, mammal, reptile) is provided in Supplementary Material 2.

\begin{tabular}{|c|c|c|c|}
\hline Index & Description & $\begin{array}{l}\text { No. of } \\
\text { species }\end{array}$ & $\begin{array}{l}\text { No. of } \\
\text { populations }\end{array}$ \\
\hline Utilized species & Based on trends in species that are utilized by humans & 1,501 & 6,214 \\
\hline Utilized freshwater species & $\begin{array}{l}\text { Based on trends in species that are found in a broad range of temperate } \\
\& \text { tropical freshwater habitats \& utilized by humans }\end{array}$ & 446 & 2,256 \\
\hline Utilized marine species & $\begin{array}{l}\text { Based on trends in species that are found in a broad range of temperate } \\
\text { \& tropical marine habitats \& utilized by humans }\end{array}$ & 388 & 1,650 \\
\hline Utilized terrestrial species & $\begin{array}{l}\text { Based on trends in species that are found in a broad range of temperate } \\
\& \text { tropical terrestrial habitats \& utilized by humans }\end{array}$ & 795 & 2,302 \\
\hline Species used for food & Based on trends in species that are utilized by humans for food & 892 & 4,500 \\
\hline Species used for sport hunting & Based on trends in species that are utilized by humans for sport hunting & 514 & 3,423 \\
\hline Species used as pets & Based on trends in species that are utilized by humans as pets & 907 & 3,624 \\
\hline Substantially used species & $\begin{array}{l}\text { Based on trends in species that are substantially utilized by humans } \\
\text { (based on scale of trade or volume of harvest at local, national, } \\
\text { regional \& international levels) }\end{array}$ & 187 & 1,100 \\
\hline Utilized Arctic species & $\begin{array}{l}\text { Based on trends in freshwater, marine \& terrestrial Arctic species that } \\
\text { are utilized by humans }\end{array}$ & 147 & 663 \\
\hline Harvest index & $\begin{array}{l}\text { Combines population \& harvest data to track the sustainability of the harvest } \\
\text { of selected utilized Arctic species }\end{array}$ & 20 & 73 \\
\hline
\end{tabular}

Vertebrate Arctic species were coded as utilized by humans based on expert opinion (C. Zöckler, pers. comm.), generating a list of utilized Arctic species.

Indices calculated We extracted data from the datasets of utilized species, substantially utilized species and utilized Arctic species and used them to generate a series of indices to assess change in populations of wild species used as commodities: (a) utilized species; (b) utilized freshwater species; (c) utilized marine species; (d) utilized terrestrial species; (e) species used to provide food for humans; (f) species used for sport hunting; (g) species used as pets; (h) substantially used species; (i) utilized Arctic species (Table 1). The number of species and populations in each dataset are further categorized by system (freshwater, marine, terrestrial), zone (temperate, tropical) and vertebrate group (amphibian, bird, fish, mammal, reptile) in Supplementary Material 2.

Calculation of indices We calculated the indices of utilized and substantially used species using the technique developed for the global Living Planet Index (Loh et al., 2005; Collen et al., 2009). The Index was calculated using population time series data (1970-2007) for 6,214 populations of 1,501 species coded as utilized and 1,100 populations of 187 species coded as substantially used. The changes in the population size of each species were aggregated and presented as an index relative to the population size in 1970, which was given a value of 1 . Tropical and temperate species were weighted equally within each system (freshwater, marine, terrestrial) to account for the over-representation of temperate compared to tropical species.
We calculated the index of utilized Arctic species, using the technique developed for the Arctic Species Trend Index (McRae et al., 2010), with time series data from 1970-2007 for 663 populations of 147 Arctic species coded as utilized. We are aware that the Arctic Species Trend Index database has been updated and a new Index has been generated since we conducted our analyses (Eamer et al., 2012); however, because the overall pattern of Arctic vertebrate abundance has not changed, we only include comparisons of our results with the trend line published in 2010 (McRae et al., 2010). We are mindful of the revised, disaggregated regional and system differences depicted in the trend line published in 2012 (Eamer et al., 2012).

Following Loh et al. (2005) as adapted by Collen et al. (2009), we used a bootstrap re-sampling technique to generate annual 95\% confidence intervals (CI) around each index value (10,00o iterations).

\section{Harvest Index}

The Harvest Index is the ratio of the estimated annual harvest rate to the potential for biological recovery (the theoretical maximum recovery rate). If the harvest rate exceeds the recovery rate this implies that the harvest rate is more likely to be unsustainable. Annual population recovery rates are estimated using a simple equation, the potential biological removal (PBR) model (Wade, 1998), derived from insights gained from simple theoretical models that are principally based on the logistic equation (Elert, 2007). 
(a)

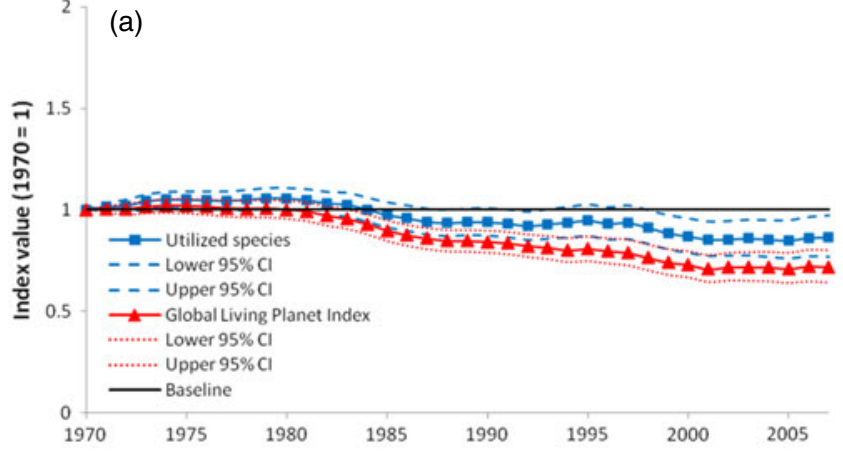

(c)

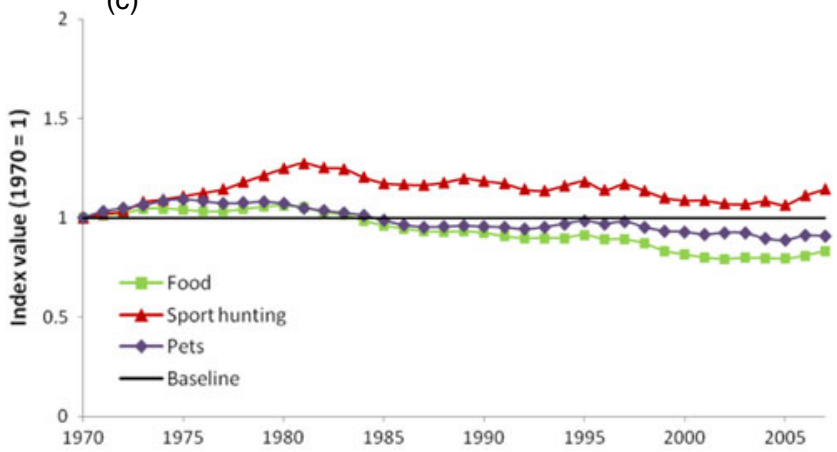

(b)

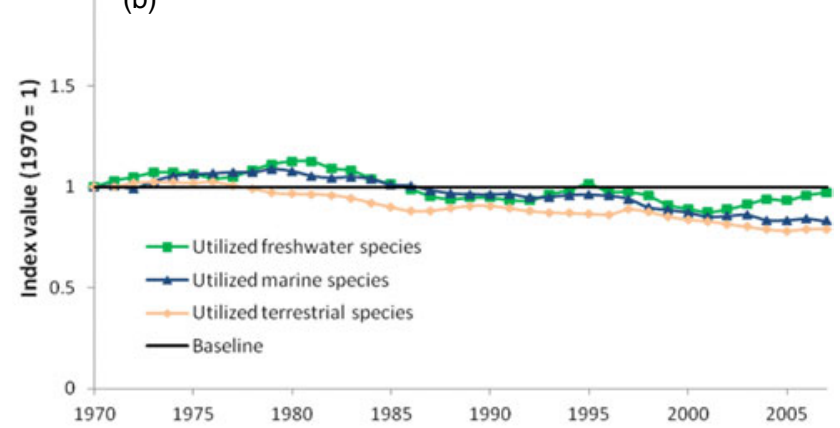

(d)

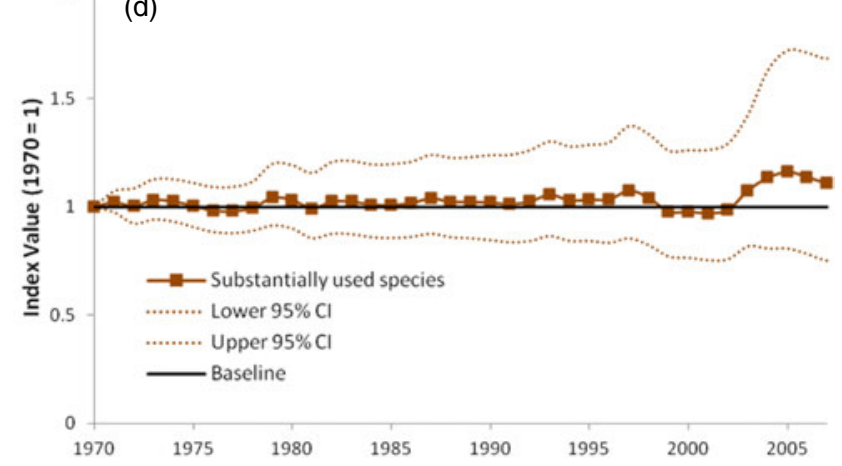

FIG. 1 Trends $( \pm 95 \%$ CI) in (a) utilized species compared to the global Living Planet Index (WWF, 2012); (b) utilized freshwater, marine and terrestrial species; (c) species used as food for humans, for sport hunting, or as pets; and (d) substantially used species in evidence categories 3, 4 or 5, between 1970 and 2007. Confidence intervals are not shown for (b) and (c) to illustrate clearly the main trends; they are provided in Supplementary Material 3.

The Harvest Index was calculated as follows:

Step 1 We calculated the potential biological removal for each population for each year. This is the maximum number of individuals that can be harvested while still allowing the maximum stable population to be reached or maintained:

$$
\operatorname{PBR}_{(t)}=n_{(t) \min } \times\left(0.5 \times R_{\text {max }}\right) \times F_{R}
$$

where $n_{(t) \min }$ is an estimate of the minimum number of individuals in the population at time $t$. As population sizes are difficult to measure accurately, this component is routinely estimated as $90 \%$ of the number of individuals thought to be present (Wade, 1998). $R_{\max }$ is the maximum theoretical productivity rate of the species. This parameter varies within a species between populations. If unknown, this value is given a weight of 0.5 , which is considered a conservative estimate of the current net production of a depleted population (Wade, 1998). $F_{R}$ represents a recovery factor. It is the proportion of the net production of the population that contributes to population growth (default value $=0.5$ ).

Step 2 At each time point $(t)$ we calculated the ratio between PBR (i.e. the theoretically sustainable harvest) and the actual number of individuals harvested $(\mathrm{H})$ :

$$
H_{(t) \text { ratio }}=H_{(t)} / \operatorname{PBR}_{(t)}
$$

We calculated PBR and $\mathrm{H}$ for all populations of a species from the mean PBR and mean $\mathrm{H}$ of each individual population of that species.

Step 3 We calculated the Harvest Index (HI) from the geometric mean of all populations for each time point. If $\mathrm{HI}>1.5$ the harvest is unsustainable (coded as being in the red zone); if $\mathrm{HI}<0.5$ the harvest is within sustainable limits (coded as being in the green zone); and if $\mathrm{HI}$ is $0.5^{-1.5}$ the harvest is on the threshold of sustainable limits (coded as being in the orange zone).

We calculated the Harvest Index for species in the utilized Arctic species dataset for which harvest data were available: 73 populations of 20 species of birds, fish and mammals (Table 1). Harvest data were recorded by volume or number of individuals taken.

\section{Results}

Trends in utilized species The Utilized Species Index shows a decline of c. 14\% between 1970 and 2007 (Fig.1a; 2007 Utilized Species Index 0.86, 95\% CI 0.77-0.97). It started to decline at about the same time as the global Living Planet Index (early 1980s) but by approximately half the amount (Fig.1a; Living Planet Index 0.72, 95\% CI 0.64-0.80). 
(a)

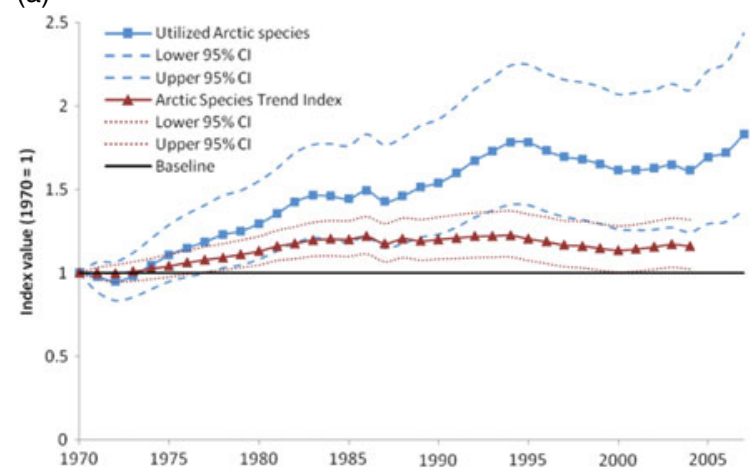

(b)

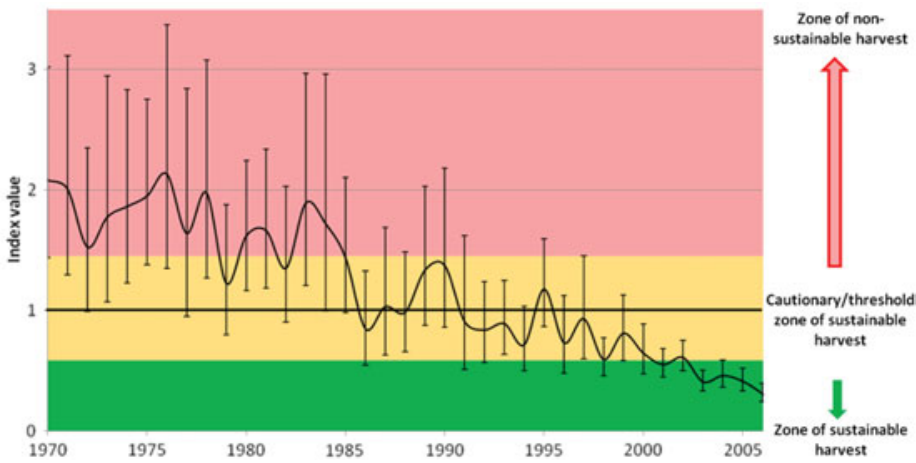

Fig. 2 Trends $( \pm 95 \%$ CI) in (a) utilized Arctic species compared to the Arctic Species Trends Index (McRae et al., 2010) between 1970 and 2007 and (b) Harvest Index of Arctic species between 1970 and 2006, with zones of unsustainable, cautionary and sustainable harvest levels shown.

The Utilized Species Index is based on trends in amphibian, bird, fish, mammal and reptile species from freshwater, marine and terrestrial systems worldwide but $88 \%$ of the time-series data used to generate this global index relate to birds (Supplementary Material 2).

Trends in utilized freshwater, marine and terrestrial vertebrate species Trends in utilized species from each system vary: between 1970 and 2007 populations of utilized freshwater species declined by c. 3\% (2007 Freshwater Utilized Species Index 0.97, 95\% CI 0.78-1.23), populations of utilized marine species by c. $17 \%$ (2007 Marine Utilized Species Index 0.83 , 95\% CI $0.66-1.04$ ), and populations of utilized terrestrial species by c. $21 \%$ (2007 Terrestrial Utilized Species Index 0.79, 95\% CI 0.68-0.93; Fig.1b). Since the early 2000 s the rate of decline of utilized marine and terrestrial species indices has slowed or stabilized. The utilized freshwater species index has increased steadily since 2000 .

Trends in utilized vertebrate species according to use Trends are variable depending on the type of use. Fig.1c shows trends for species used as food for people, for hunting by humans for sport, or as pets. These categories are not mutually exclusive and the majority of species have more than one use. Therefore some species may be represented in more than one trend line. The index for species used to provide food for humans and that for species used as pets declined by c. $17 \%$ (2007 Food Utilized Species Index 0.83 , 95\% CI $0.72-0.97$ ) and c. 9\% (2007 Pets Utilized Species Index $0.91,95 \%$ CI $0.77-1.08$ ), respectively, between 1970 and 2007; however, both have stabilized since the early 2000s. The index for species hunted by humans increased by c. $14 \%$ overall between 1970 and 2007 (2007 Sports Hunting Utilized Species Index 1.14, 95\% CI 0.94-1.42) but the pattern has varied over time, with the index increasing between 1970 and the early 1980s, followed by a slow decline until c. 2005, and then increasing again in recent years. The indices track changes in populations of amphibian, bird, fish, mammal and reptile species from freshwater, marine and terrestrial systems but the data are biased towards birds and fish (Supplementary Material 2).

Trends in substantially used vertebrate species This index tracks changes in populations of bird, fish, mammal and reptile species that are widely traded and used at local, national, regional and international levels (Supplementary Material 2). Apart from an apparent rise in the early 2000 s there has been no change in the populations of these species since 1970 (Fig. 1d; 2007 Substantially Utilized Species Index 1.11, 95\% CI 0.75-1.68). Data are biased towards fish and mammals (Supplementary Material 2).

Trends in utilized Arctic species Populations of utilized Arctic species showed an upward trend between 1970 and 2007, increasing by 83\% (Fig.2a: Arctic Utilized Species Index 1.83, 95\% CI 0.84-2.44). By contrast, the Arctic Species Trend Index increased by $16 \%$ between 1970 and 2004 (Fig. 2b; 2004 Arctic Species Trend Index 1.16, 95\% CI 1.021.32; McRae et al., 2010). The trend in utilized Arctic species has not been constant, rising between 1970 and 1994 and then undergoing a period of apparent stabilization before rising again in 2005. This index is based on bird, fish and mammal species only, from freshwater, marine and terrestrial systems (Supplementary Material 2).

\section{Harvest Index}

This index reflects trends in the harvest and stock estimates of Arctic species of birds, fish and mammals. Harvest levels between 1970 and 1985 were generally predicted to be unsustainable (i.e. they were in the red zone; Fig.2b). However, the Harvest Index has shown a steady decrease, from $>2.0$ in 1976 to c. 0.3 in 2006, indicating that the overall level of harvesting is now within predicted sustainable limits (green zone). For many years (1985 to early 2000s) the harvest levels fluctuated around predicted 
sustainable harvest thresholds (orange zone). However, a number of individual populations (particularly fish) are still predicted as being over-harvested.

\section{Discussion}

Indicators that can track changes in populations of species used by humans are essential tools for measuring progress towards ensuring the sustainable use of living resources. The two indicators presented here have the potential to provide valuable input into future guidelines for the sustainable use of wild species at global, regional and national levels and, after further development, could be incorporated into future sets of indicators to track progress towards global biodiversity targets.

\section{Global trends in the Utilized Species Index}

At a global level the Utilized Species Index shows a decline of c. $14 \%$ between 1970 and 2007 , implying that use of these species has not been sustainable. There has been a relatively steady decline since the early 1980 s but there have been signs of stabilization in recent years. Although it was not possible to generate a separate index of non-utilized species (given that a lack of evidence for use does not mean that non-use can be assumed) and compare trends of non-utilized and utilized species, it was possible to compare the Utilized Species Index with the global Living Planet Index, which includes species whether their use is known or not. Trend lines of both indicators showed similar trajectories but the Utilized Species Index only declined by about half as much as the Living Planet Index. This suggests that, in general, utilized species are faring better than other species. This could be because people are more likely to use and rely on common, more easily exploited species than rare ones or because populations of utilized species are likely to be managed more effectively or are under greater protection than populations of non-utilized species. This creates what could be a paradoxical situation in terms of conservation management, whereby species subjected to significant utilization have a lower risk of being threatened (i.e. a 'use it or lose it' scenario). Similarly, the Red List Index of Threatened Species has shown that the conservation status of known utilized species, particularly birds, is better than that of non-utilized species and that they face a lower risk of extinction (Butchart, 2008).

The concept of this 'use it or lose it' scenario is further strengthened when the trend in substantially used species is examined. This index includes species that are most widely used and are considered most important to people. Although the confidence intervals are relatively broad (partly because of reduced sample sizes) the trend shows no overall change in the size of these populations. When compared with the Utilized Species Index this suggests that species that are used more widely or more intensely are likely to be less threatened than species with a lower incidence of use.

Differences in trends between three use categories (food, sport hunting and pets) also support the idea of 'use it or lose it'. Although populations of vertebrates used for food and pets declined below the 1970 baseline, suggesting their use is unsustainable, the trend for species that are hunted for sport has remained relatively stable after an initial rise from the start of the index. This may be because in many places sport hunting has become more highly regulated (Lamoureux, 1999; Robinson et al., 2008; Reid et al., 2010).

Trends in wild commodities indicators for Arctic species

A majority of Arctic species are utilized in commercial, subsistence or traditional harvest and trade. It is evident that both local and global environmental and economic changes since the 1950 s have altered and complicated harvest trends in the Arctic and are exerting increasing pressure on Arctic biodiversity (CAFF, 2010) but there is still a limited understanding of how Arctic wildlife populations are responding to these changes.

The wild commodities indicators we calculated for Arctic species provide an initial insight into the response of utilized species to these pressures. The Arctic Utilized Species Index shows that the mean abundance of utilized Arctic vertebrates increased by $83 \%$ between 1970 and 2007 . The greatest increase occurred between 1970 and 1994, followed by a slight decline and stabilization until 2005. The trend appears to be rising since then. This increase is five times higher than that observed for all species in the 2010 Arctic Species Trend Index, which increased by $16 \%$ between 1970 and 2004 (McRae et al., 2010). This implies that, in general, utilized Arctic species are faring better than all other Arctic vertebrate species for which data are available, particularly since the early to mid 1990s, as indicated by minimal overlap between the confidence intervals of the Arctic Utilized Species Index and the Arctic Species Trend Index.

The increasing trend in the Arctic Species Trend Index may be partly driven by the recovery of some vertebrate populations (e.g. marine mammals) from historical overharvesting, as well as the rapid increase of some populations (e.g. Bering Sea pollock species and lesser snow goose Chen caerulescens caerulescens) both inside and outside the Arctic as a result of recent environmental changes (CAFF, 2010). These reasons could also help explain the trend in the Arctic Utilized Species Index.

Further insight can be gained by examining trends of the Arctic Species Trend Index and the Arctic Utilized Species Index alongside those of the Harvest 
Index developed and presented here. The Harvest Index combines data on biological characteristics of a species with information on population changes and harvest levels to determine a threshold above which harvested individuals can be replaced. When applied to a subset of utilized Arctic species it indicated that harvest levels have become more sustainable since 1970 and, although it is not known if they have recovered to pre-exploitation levels, they are now likely to be within sustainable limits. This could also help to explain the increasing trend observed in populations of utilized Arctic species. It also highlights that examining related indicators together instead of in isolation can reveal more information about the potential responses of various taxa to human-induced and natural pressures.

\section{Strengths of wild commodities indicators}

Both the Utilized Species Index and the Harvest Index are relatively easy to understand and communicate conceptually and empirically. They are tractable, with data on most species available for a long time-period. They appear to be responsive to change and, given the growing demand to develop tools for addressing issues related to sustainable use of wild species (Hutton \& Leader-Williams, 2003; UNEP/CBD/COP/11/2, 2001), are relevant to policy. However, the ultimate test of their effectiveness will be if they are used to measure progress, enhance understanding or raise awareness of these issues (Biodiversity Indicators Partnership, 2011).

The Utilized Species Index, like the Living Planet Index upon which it is based, could potentially be applied at multiple scales (e.g. global, regional, national) or disaggregated to examine population trends in different systems, biomes or vertebrate classes, thereby providing further insight into overall trends. Although it was not possible to disaggregate the Utilized Species Index by vertebrate class because of insufficient sample sizes, we were able to examine trends by system. We observed different trends in the abundance of populations of freshwater, marine and terrestrial species. Although populations in all three systems have declined since 1970 they have done so at different rates, and populations of freshwater species appear to be increasing in recent years. Similar patterns were seen in the global Living Planet Index (WWF, 2012). It was not possible to examine trends in utilized Arctic species disaggregated by region (e.g. high, low, sub-Arctic), ecological system or vertebrate class because sample size was inadequate. However, there are likely to be significant differences between these categories, as seen in the latest Arctic Species Trend Index (Eamer et al., 2012). For example, trends in population abundance of sea-ice dependent species of the high Arctic currently show a decline (McRae et al., 2010; Eamer et al., 2012). It is not known exactly why differences between systems or classes exist in species indices but they could be partly determined by the availability of underlying data (see further discussion below).

The Harvest Index is an extension of the established and tested potential biological removal model (Wade, 1998; Johnston et al., 2000; Milner-Gulland \& Akcakaya, 2001; Marsh et al., 2004), which is relatively simple, adopts a precautionary approach in its assumptions and accounts for some of the uncertainties in the parameters it uses (Wade, 1998; Milner-Gulland \& Akcakaya, 2001; Cooke et al., 2012).

\section{Limitations of wild commodities indicators}

A limitation of both indicators is that they rely on estimates of total population size, which can be difficult to obtain. Estimates are more commonly available for only part of a population in part of its range, which may not be fully representative of the species. Furthermore, population estimates may not always be from harvested populations. We coded data to the species level, therefore populations that are not utilized may be contributing to the index. The specificity of the indices could be improved by coding threats at the population level. Although difficult, this should be attempted where possible so that only estimates from harvested populations are used in calculations of the wild commodities indicators.

A second limitation of both indicators is that not all populations, taxa, systems and regions are adequately represented: at the global level more data are available for tropical areas; in the Arctic there is a lack of crucial data for many fish, most whales and seals, and the polar bear Ursus maritimus. The Utilized Species Index accounts to some extent for the imbalance of geographical representativeness by weighting species evenly in tropical and temperate regions but it is more difficult to address biases introduced by over-representation of certain vertebrate classes (Loh et al., 2005; Collen et al., 2009). The majority of data underlying both the global and Arctic Utilized Species Indices were from birds, followed by fish and then mammals. This does not invalidate the indices if, in fact, more bird species are used or threatened by use. However, there is a considerable lack of data on how many species in each vertebrate class are used and how much is harvested. For example, data on harvested Arctic species are biased towards marine mammal and marine fish populations, which could mask declines in some seabird colonies that are over-harvested. Once these factors are known the representativeness of a dataset can be assessed and potential biases accounted for. Therefore, prioritizing research and monitoring programmes to fill data gaps in underrepresented classes will make these indices more robust and 
enhance their usefulness in providing guidance for wildlife management and in tracking sustainable use.

Other limitations are indicator specific. For most populations of species in the Utilized Species Index it is likely that the cause of decline is not attributable solely to harvesting. For example, the house sparrow Passer domesticus, which is used in traditional Chinese medicine, may be harvested intensively in some parts of Asia but is unlikely to be harvested at a similar level in other parts of its range. Therefore this index can reflect changes in the species people use and, by proxy, their availability to people, but as yet it cannot determine the extent to which use is a driver of those changes. To improve this it may be possible to classify each population in the index by cause of decline. However, diagnosing threats can be difficult because of the diverse nature of both threatening processes and the response of species to threats, resulting in a heterogeneous distribution of threats globally, certain species being intrinsically more threatened by specific factors (Owens \& Bennett, 2000; Purvis et al., 2000; Isaac \& Cowlishaw, 2004; Kotiaho et al., 2005; Price \& Gittleman, 2007; Corey \& Wait, 2008; Thomas, 2008), and non-linear population responses to particular extrinsic pressures (Lomolino \& Channell, 1995; Rodriguez, 2002; Thomas, 2008). Therefore a decline in the index does not imply that use is universally detrimental to the species, that use in every population is unsustainable or that reducing harvest pressure will result in improved trends, particularly if other factors are driving negative trends.

For the Harvest Index, in addition to incorporating data from a broader range of species, we recommend four steps to improve its development. (1) Harvest and population abundance estimates should ideally be from the same population to avoid skewing estimates of harvest sustainability. (2) It is recognized that $R_{\max }$ values for many species are uncertain. Therefore $R_{\max }$ should ideally be based on maximum likely rates of recovery observed in field studies rather than on theoretical principles, especially for high $R_{\max }$ species. High $R_{\max }$ species may have high recovery potential but may also have highly variable population dynamics that could result in misrepresentative estimates of $n_{\text {min }}$ and population status. (3) The estimate of $F_{R}$ is currently set to 0.5 because of a lack of information. However, $F_{R}$ is likely to vary between species, depending on a variety of population parameters, such as how population numbers fluctuate in response to density dependence. Therefore efforts need to be concentrated on obtaining data to calculate species-specific $F_{\mathrm{R}}$ values. This would help to improve the precision of the indicator and interpretation of trends. (4) Populations should be between their potential biological removal abundance and carrying capacity. If the method is used on over-depleted populations the index will not yield correct results; even harvests less than the potential biological recovery will be unsustainable if they exceed the rate of recovery of a heavily depleted population

\section{Recommendations}

To provide a complete picture of the trade and use of a given species we need information on the status of the species in the wild (supply), the volume of products from the species on the market (demand) and the relationship between the two. The wild commodities indicators presented here currently provide information on supply only; i.e. trends in individual source populations over time or trends in the amount and sustainability of harvests. Future work, in addition to addressing the caveats outlined above, should focus on developing a complementary indicator for demand; i.e. an indicator that can be used to track changes in market value and market size for wild commodities, and improving our understanding of the feedback between supply and demand.

For Arctic species there is a need for more information on whether species are used inside or outside the Arctic region. Many migratory species that breed in the Arctic (such as geese, plovers, some fish, sharks and whales) and hence are classified as Arctic species are almost exclusively harvested outside of the Arctic region. Identifying trends in these species is likely to be important for establishing management plans.

In conclusion, although the wild commodities indicators presented here are still limited in their utility and reliability they have the potential to be useful indicators of sustainable use. A concerted effort by researchers and decision-makers to make more data available and broaden their scope will strengthen them as tools for policy and reporting.

\section{Acknowledgements}

This work was generously funded by the Stichting Shell Research Foundation and was carried out under the auspices of the Biodiversity Indicators Partnership. We thank the Steering Group Committee members for their expertise and guidance: Steven Broad (TRAFFIC), Stuart Butchart (BirdLife International), Holly Dublin (IUCN Species Survival Commission), Craig Hilton-Taylor (IUCN Species Survival Commission), Georgina Mace (Imperial College London), Thomasina Oldfield (TRAFFIC), and Matthew Smith (Microsoft Development). We would also like to thank Alison Johnston (BTO) for statistical advice, and Tom Barry (CAFF) and Mike Gill (Environment Canada), plus two anonymous referees for valuable comments. 


\section{References}

Avibase (2009) Avibase - the world bird database. Http://avibase.bsceoc.org [accessed September 2009].

Baillie, J.E.M., Griffiths, J., Turvey, S.T., Loh, J. \& Collen, B. (2010) Evolution Lost: Status and Trends of the World's Vertebrates. Zoological Society of London, UK.

Biodiversity Indicators Partnership (2011) Guidance for National Biodiversity Indicator Development and Use. UNEP World Conservation Monitoring Centre, Cambridge, UK. Http://www. bipnational.net/LinkClick.aspx?fileticket $=6 \mathrm{JNUXXo6xOA} \%$ $3 \mathrm{~d} \&$ tabid=38\&language $=$ en-US [accessed 10 March 2012].

Butchart, S.H.M. (2008) Red List Indices to measure the sustainability of species use and impacts of invasive alien species. Bird Conservation International, 18, S245-S262.

Butchart, S.H.M., Walpole, M., Collen, B., van Strien, A., Scharlemann, J., Almond, R. et al. (2010) Global biodiversity declines continue. Science, 328, 1164-1168.

CAfF (Conservation of Arctic Flora and Fauna) (2010) Arctic Biodiversity Trends 2010: Selected Indicators of Change. CAFF International Secretariat, Akureyri, Iceland.

CBD (Convention on Biological Diversity) (1992) Text of the CBD: Article 2. Use of Terms. Http://www.cbd.int/convention/ articles/default.shtml?a=cbd-02 [accessed 4 March 2012].

CBD (Convention on Biological Diversity) (2010a) Report of the Tenth Meeting of the Conference of the Parties to the Convention on Biological Diversity. UN Environment Programme, Nairobi, Kenya.

CBD (Convention on Biological Diversity) (2010b) Report of the Fourteenth Meeting of the Subsidiary Body on Scientific, Technical and Technological Advice. UN Environment Programme, Nairobi, Kenya.

CIFOR (2009) Center for International Forestry Research. Http:// www.cifor.org/ [accessed September 2009].

Cites (Convention on International Trade in Endangered Species of Wild Fauna and Flora) (2009) CITES trade database. Http://www.cites.org/eng/resources/trade.shtml [accessed September 2009].

Collen, B., Loh, J., Whitmee, S., McRae, L., Amin, R. \& B AILLIE, J.E.M. (2009) Monitoring change in vertebrate abundance: the Living Planet Index. Conservation Biology, 23, 317-327.

Cooke, J., Leaper, R., Wade, P.R., Lavigne, D.M. \& Taylor, B. (2012) Management rules for marine mammal populations: a response to Lonergan. Marine Policy, 36, 389-392.

Corey, S.J. \& Wait, T.A. (2008) Phylogenetic autocorrelation of extinction threat in globally imperilled amphibians. Diversity and Distributions, 14, 614-629.

Eamer, J., Russell, D.E., McRae, L., Böhm, M., Deinet, S., Collen, B. \& Gill, M.J. (2012) Arctic Species Trend Index: Key Findings from an In-depth Look at Marine Species and Development of Spatial Analysis Techniques. Http://www.caff.is/asti [accessed 7 April 2012].

Elert, G. (2007) The Chaos Hypertextbook. Http://hypertextbook. com/chaos/ [accessed 15 February 2012].

FaO (Food and Agriculture Organization of the United NAtions) (2009a) FAO Forestry Country Information. Http://www. fao.org/forestry/country/en/ [accessed September 2009].

FAO (Food and Agriculture Organization of the United Nations) (2009b) Global Forest Resources Assessments. Http:// www.fao.org/forestry/fra/ [accessed September 2009].

Froese, R. \& Pauly, D. (eds) (2009) FishBase, version (09/2009). Http:// www.fishbase.org [accessed 18 December 2013].

Gill, M.J., Raillard, M.C., Zöckler, C. \& Smith, R.B. (2008) Developing an Integrated and Sustained Arctic Biodiversity
Monitoring Network: CBMP Five-Year Implementation Plan. CAFF International Secretariat, Akureyri, Iceland.

Gleason, J.S. \& Rode, K.D. (2009) Polar bear distribution and habitat association reflect long-term changes in fall sea ice conditions in the Alaskan Beaufort Sea. Arctic, 62, 405-417.

Heide-Jørgensen, M.P., Laidre, K.L., Borchers, D., Marques, T.A., Stern, H. \& Simon, M. (2010) The effect of sea-ice loss on beluga whales (Delphinapterus leucas) in West Greenland. Polar Research, 29, 198-208.

Hutton, J.M. \& Leader-Williams, N. (2003) Sustainable use and incentive-driven conservation: realigning human and conservation interests. Oryx, 37, 215-226.

IsaAC, N.J.B. \& Cowlishaw, G. (2004) How species respond to multiple extinction threats. Royal Society of London B, 271, 1135-1141.

ITTO (2009) International Tropical Timber Organization. Http:// www.itto.int/ [accessed September 2009].

IUCN (2009) IUCN Red List of Threatened Species v. 2009. Http:// www.iucnredlist.org [accessed September 2009].

Johnston, D.W., Meisenheimer, P. \& Lavigne, D.M. (2000) An evaluation of management objectives for Canada's commercial harp seal hunt, 1996-1998. Conservation in Practice, $14,729-737$.

Kotiaho, J.S., Kaitala, V., Komonen, A. \& Paívinen, J. (2005) Predicting the risk of extinction from shared ecological characteristics. Proceedings of the National Academy of Sciences of the USA, 102, 1963-1967.

Kovacs, K., Lydersen, C., Overland, J. \& Moore, S. (2010) Impacts of changing sea-ice conditions on Arctic marine mammals. Marine Biodiversity, 41, 1-14.

Lamoureux, J. (1999) Effects of selective harvest on moose populations of the Bas-Saint-Laurent region, Quebec. ALCES, 35, 91-202.

Loh, J., Green, R.E., Ricketts, T., Lamoreux, J., Jenkins, M., Kapos, V. \& Randers, J. (2005) The Living Planet Index: using species population time series to track trends in biodiversity. Philosophical Transactions: Biological Sciences, 360, 289-295.

Lomolino, M.V. \& Channell, R. (1995) Splendid isolation: patterns of geographic range collapse in endangered mammals. Journal of Mammology, 78, 335-347.

Marsh, H., Lawler, I.R., Kwan, D., Delean, S., Pollock, K. \& Alldredge, M. (2004) Aerial surveys and the potential biological removal technique indicate that the Torres Strait dugong fishery is unsustainable. Animal Conservation, 7, 435-443.

McRae, L., Zöckler, C., Gill, M., Loh, J., Latham, J., Harrison, N. et al. (2010) Arctic Species Trend Index 2010: Tracking Trends in Arctic Wildlife. Http://www.caff.is/publications/ view_document/30-arctic-species-trend-index-2010-trackingtrends-in-arctic-wildlife [accessed 11 November 2011].

Milner-Gulland, E.J. \& Akcakaya, H.R. (2001) Sustainability indices for exploited populations. TRENDS in Ecology and Evolution, 16, 686-692.

Owens, I.P.F. \& Bennett, P.M. (2000) Ecological basis of extinction risk in birds: habitat loss versus human persecution and introduced predators. Proceedings of the National Academy of Sciences of the USA, 97, 12144-12148.

Post, E., Forchhammer, M.C., Bret-Harte, M.S., Callaghan, T.V., Christensen, T.R., Elberling, B. et al. (2009) Ecological dynamics across the Arctic associated with recent climate change. Science, 325, 1355-1358.

Price, S.A. \& Gittleman, J.L. (2007) Hunting to extinction: biology and regional economy influence extinction risk and the impact of hunting in artiodactlys. Proceedings of the Royal Society of London B, 274, 1845-1851. 
Purvis, A., Gittleman, J.L., Cowlishaw, G. \& Mace, G.M. (2000) Predicting extinction risk in declining species. Proceedings of the Royal Society of London B, 267, 1947-1952.

Reid, N., Magee, C. \& Montgomery, W.I. (2010) Integrating field sports, hare population management and conservation. Acta Theriologica, 55, 61-71.

Robinson, H.S., Wielgus, R.B., Cooley, H.S. \& Cooley, S.W. (2008) Sink populations in carnivore management: cougar demography and immigration in a hunted population. Ecological Applications, 18, 1028-1037.

Rodriguez, J.P. (2002) Range contraction in declining North American bird populations. Ecological Applications, 12, 238-248.

Sparks, T.H., Butchart, S.H.M., Balmford, A., Bennun, L., Stanwell-Smith, D., Walpole, M. et al. (2011) Linked indicator sets for addressing biodiversity loss. Oryx, 45, 411-419.

Thomas, G.H. (2008) Phylogenetic distributions of British birds of conservation concern. Proceedings of the Royal Society of London B, 275, 2077-2083.

UbC (University of British Columbia) (2009) Sea Around Us Project. Http://www.seaaroundus.org [accessed September 2009].
W ADE, P.R. (1998) Calculating limits to the allowable human-caused mortality of cetaceans and pinnipeds. Marine Mammal Science, $14,1-37$.

Walpole, M., Almond, R., Besançon, C., Butchart, S.H.M., Campbell-Lendrum, D., Carr, G.M. et al. (2009) Tracking progress towards the 2010 Biodiversity Target and beyond. Science, 325, 1503-1504.

WWF (2012) Living Planet Report 2012. Http://awsassets.panda.org/ downloads/1_lpr_2012_online_full_size_single_pages_final_120516. pdf [accessed 20 July 2012].

\section{Biographical sketches}

This article was initiated as part of the Biodiversity Indicators Partnership (http://www.bipindicators.net/), which is coordinated by the United Nations Environment Programme World Conservation Monitoring Centre. The authors, based in Cambridge and London, UK, and the Wageningen, The Netherlands, all work on a broad range of topics in conservation science, specializing in the development and use of global and national biodiversity indicators for tracking progress towards policy targets. 